\title{
A Independência da Escolha dos Canais de Marketing nas Rendas dos Produtores Orgânicos Americanos ${ }^{1,2}$
}

\author{
Andréa Rossi Scalco ${ }^{3}$, Roberta Souza ${ }^{4}$, \\ Willerson Lucas Campos-Silva ${ }^{5}$ e Gregory Baker ${ }^{6}$
}

Resumo: Uma das atividades relacionadas às estratégias de captura valor na atividade produtiva de orgânico refere-se à escolha dos canais adequados de distribuição dos produtos. A literatura aponta a importância de analisar os ganhos dos pequenos produtores com respeito aos canais de distribuição de produtos orgânicos. A literatura indica que a comercialização em canais diretos pode fazer com que pequenos produtores possam capturar maior valor e, consequentemente, incrementar sua renda. Foi realizada uma pesquisa empírica no estado da Califórnia, nos Estados Unidos da América, por meio de um survey com 60 produtores de orgânicos, a fim de identificar se os canais de distribuição diretos são prioritariamente utilizados por pequenos produtores. Os resultados indicam que a escolha dos canais de distribuição, venda direta ou indireta, além do tipo de canal dentro dessa categorização, não está diretamente relacionado apenas à renda que o produtor pode obter. Há indicações de que a escolha do canal adequado esteja mais relacionada às motivações do produtor rural, em relação à qualidade de vida e perspectivas de crescimento do seu negócio, além da opção pela diversificação dos canais para diminuir os riscos envolvidos na comercialização de seus produtos.

Palavras-chaves: canais de distribuição, valor, orgânico.

Abstract: One of the issues related to strategies for capturing value in organic production activities is the decision regarding the appropriate product distribution channel. The literature points out the importance of analyzing the gains of organic small producers concerning the marketing channels for organic products. Research indicates that marketing through direct channels is an advantage for

1. Data de submissão: 30 de junho de 2016. Data de aceite: 21 de julho de 2017.

2. Agradeço à Capes (Coordenação de Aperfeiçoamento de Pessoal de nível Superior) pela bolsa concedida para realização desta pesquisa, à Universidade Estadual Paulista, que proporcionou o afastamento para realização de estágio em pesquisa, e do Food and Agribusiness Institute at Santa Clara University, onde foi conduzido o estágio em pesquisa.

3. Universidade Estadual Paulista “Júlio de Mesquita Filho". Tupã, SP, Brasil. E-mail: andrea@tupa.unesp.br

4. Escola Politécnica da USP. São Paulo, SP, Brasil. E-mail: csouzaroberta@gmail.com

5. Escola Politécnica da USP. São Paulo, SP, Brasil. E-mail: willerson.silva@usp.br

6. Santa Clara University. Estados Unidos. E-mail: gbaker@scu.edu 
small producers since these channels promote increased value capture and, consequently, increased income. Empirical research was conducted in California, United States, in which 60 organic producers were surveyed to determine whether direct distribution is the preferred type of distribution channel utilized by small producers. The results indicate that the choice of distribution channel, direct or indirect, and the type of channel within this category, is not directly related to producer income. There are indications that the choice of the appropriate channel is more connected to producers' motives, quality of life, and perspectives on the growth of their business. Moreover, diversification of marketing channels may be an important mechanism to reduce the risks involved in the marketing their products.

Key-words: distribution channels, value capture, organic.

Classificação JEL: Q13.

DOI: http://dx.doi.org/10.1590/1234-56781806-94790550409

\section{Introdução}

Sistemas alternativos de produção foram sendo desenvolvidos durante décadas e defendiam práticas alternativas de produção para inserção de pequenos e médios produtores (GONZÁLEZ e NIGH, 2005; PHILLIPS e PETERSON, 2007). Em se tratando da produção orgânica, um dos principais argumentos a seu favor é a promoção de renda para pequenos e médios produtores por meio de produto diferenciado, livre de resíduos químicos. No manejo orgânico, a representatividade na produção de frutas, legumes e verduras é significativa; no entanto, ocupam áreas menores de produção se comparadas à produção de oleaginosas, cereais, café, pecuária de corte e leite (TERRAZAN e VALARINI, 2009). A grande maioria das propriedades produtoras de produtos orgânicos no mundo é caracterizada por pequenas e médias propriedades.

Os produtores, especificamente os pequenos, têm enfrentado desafios considerando a nova configuração das cadeias de valor com a concentração do setor varejista (VORLEY, 2003; VORLEY e FOX, 2004). A literatura ressalta as dificuldades enfrentadas pelos produtores em negociar sua produção com os supermercados, tendo em vista o poder de barganha das grandes redes varejistas (ELDER, LISTER e DAUVERGNE, 2014). Neste sentido, o desenvolvimento de novos canais de distribuição (ou marketing) para pequenos produtores de orgânicos é importante ao permitir maior captura de valor na realização de suas atividades, bem como melhoria nas condições de vida do produtor.
Segundo Cadilhon (2007), canais de venda direta ocorrem quando os produtores negociam seus produtos diretamente com os consumidores, por meio de diferentes mecanismos de comercialização. Segundo Wang, Moustier e Loc (2014), os canais de distribuição diretos utilizados por produtores de vegetais frescos no Vietnã têm aumentado a renda de pequenos produtores. Diante disso, o objetivo deste artigo é investigar o uso de canais diretos e indiretos, por pequenos e grandes produtores de orgânicos. O principal argumento é que pequenos produtores optariam prioritariamente por canais de distribuição diretos para garantir maior renda.

O artigo está estruturado a partir de uma breve revisão sobre produção orgânica, enfatizando a produção de orgânicos no estado da Califórnia, foco do estudo. Em seguida, são descritos os principais canais de distribuição de produtos orgânicos, diferenciando canais diretos e indiretos, além de realizar o estado da arte no que se refere à utilização dos canais diretos e indiretos pelos pequenos e médios produtores, especificamente de produtos orgânicos. Nas seções seguintes são apresentados métodos, resultados da pesquisa e as considerações finais.

\section{Produção orgânica e canais de distribuição}

A produção de orgânicos no mundo abrange cerca de 37,5 milhões de hectares em termos de ter- 
ras agriculturáveis, onde estão envolvidos cerca de 1,9 milhão de produtores em 164 países.

Os princípios da agricultura orgânica foram desenvolvidos nos Estados Unidos na década de 1970 por meio de grupos de produtores. Nos EUA, o National Research Council e o United States Department of Agriculture (USDA) desenvolveram estudos relacionados a produção rural com uso reduzido ou mesmo sem o uso de insumos químicos na década de 1980. Em 1990, por meio do USDA, foi estabelecido Food, Agriculture, Conservation, and Trade Act (FACTA), uma lei agrícola americana com o objetivo de promover ações de desenvolvimento direcionados à produção orgânica com viés para um modelo ecológico sustentável (SOUZA e ALCANTARA, 2003).

A agricultura sustentável foi institucionalizada em 1990, no Farm Bill Congress, organizado pela Facta, como Lei Pública 101-624, Título XVI, Subtítulo A, seção 1603, página 363. De acordo com esta lei,

o termo agricultura sustentável significa um sistema integrado de práticas de produção de plantas e animais que tem uma aplicação específica voltada ao local de produção em que a longo prazo irá: $(\mathrm{A})$ satisfazer às necessidades alimentares e de fibras humanas; (B) melhorar a qualidade ambiental e dos recursos naturais em que a economia agrícola depende; (C) fazer o uso mais eficiente dos recursos não renováveis e dos recursos na exploração, e integrar, quando apropriado, o controle natural dos ciclos biológicos; (D) assegurar a viabilidade econômica das operações agrícolas; (E) melhorar a qualidade de vida dos agricultores e da sociedade como um todo (FACTA, 1990, p. 363).

A partir de então, foi crescendo a participação dos organismos certificadores no setor para garantir determinados padrões de produção e processamento de produtos orgânicos. Em 1992, foi criado o National Organic Standards Board (NOSB) nos Estados Unidos, sendo constituído por produtores, processadores, atacadistas/varejistas, organismos certificadores de orgânicos, especialistas científicos em proteção ambiental e grupos de consumidores. Em 1994, esses grupos de interesse submeteram suas recomendações em termos de padrões da produção orgânica para o USDA.

Em 2001, o USDA criou o National Organic Program (NOP), responsável por desenvolver padrões nacio- nais de produtos da agricultura produzidos organicamente. Por meio desse programa foi definido que o 2002 seria o prazo final para que todos os agentes da cadeia produtiva de orgânicos se adequassem a esses padrões (MEDAETS e FONSECA, 2005; NOP, 2015).

De acordo com o USDA (2012), o número de produtores certificados aumentou $240 \%$ de 2001 para 2012. O estado da Califórnia destaca-se em termos de número de produtores, terra agricultável e vendas de produtos orgânicos. Cerca de $41 \%$ da área cultivada com produtos orgânicos nos Estados Unidos está localizada na Califórnia, sendo predominantemente representada por pequenos e médios produtores (OBERHOLTZER, DIMITRI e GREENE, 2008). Esta situação é muito semelhante à do Brasil, uma vez que $70 \%$ da produção orgânica de FLVs tem origem em pequenas propriedades familiares (SOUZA apud ALCANTARA e SOUZA, 2005).

A evolução no consumo de produtos orgânicos tem se mostrado expressiva nas duas últimas décadas de 2000. De 2002 a 2006, houve crescimento de $43 \%$ no mercado mundial de alimentos orgânicos, ou seja, de 23 bilhões de dólares para 40 bilhões de dólares (índice de crescimento de 73,9\%) (WILLER e KILCHER, 2011 apud SCALCO, OLIVEIRA e COBRE, 2015). Entre 1999 e 2007, a receita mundial de produtos orgânicos teve crescimento de 300\%. Entre 2008 e 2012, apesar de ainda em evolução crescente, a totalidade das vendas mundiais (35\%) foi menos expressiva do que no período que marcou o início do século XXI (entre 2000 e 2007); no entanto, tem se mostrado expressiva a partir de 2000 (SCALCO, OLIVEIRA e COBRE, 2015). Apesar do crescimento constante desse mercado específico, tal atividade, se comparada à atividade agrícola convencional, ainda é recente.

A produção de produtos orgânicos é representada principalmente por pequenos e médios produtores os quais foram moldados por meio de influências de movimentos voltados a questões éticas, com princípios e valores ambientais e sociais, mais do que voltados a questões de mercado. Vale ressaltar que a viabilidade econômica na produção orgânica está relacionada ao incremento de preço do produto em relação ao convencional. Um estudo realizado em uma propriedade produtora de café convencional no interior de São Paulo, após o levantamento de custos associados na produção do café convencional e posterior simulações de modelos de maximização de lucros e minimização 
de custos para conversão e manutenção da produção de café orgânico, revelou que a viabilidade econômica no sistema de produção de café orgânico é altamente dependente do adicional de preço em relação ao sistema convencional, em razão de custos associados à mão de obra e tecnologia (OLIVEIRA e CAIXETA FILHO, 2013). Outro elemento fundamental é a questão do acesso aos mercados. O alto nível de concentração de varejo, o que impõe negociação desigual entre produtores e varejo, leva a uma grande dificuldade de inserção e captura de valor por pequenos e médios produtores. No entanto, para atender à demanda crescente desse produto, tais produtores necessitam acessar canais de distribuição mais comumente utilizados para produtos convencionais. Como consequência, os produtores de orgânicos tem que se inserir neste universo caracterizado pelo alto grau de concentração do varejo (CANTOR e STROCHLIC, 2009; DIMITRI e OBERHOLTZER, 2009; DOLAN e HUMPHREY, 2000). Segundo Jandrey et al. (2016), em estudo sobre comercialização de produtos agroalimentares orgânicos na Serra Gaúcha, os principais canais de comercialização são os supermercados, seguidos das feiras. Apesar da produção de orgânicos ser recente nessa região, a comercialização começou com as feiras, mas já está se direcionando para os supermercados, mostrando uma diversidade dos canais de comercialização. Segundo Terrazan e Vallarini (2009), tanto o supermercado quanto as feiras têm papel importante na comercialização. Os primeiros são os principais, mas as feiras são os canais que oferecem maior remuneração ao produtor.

De maneira geral, os produtos orgânicos são encontrados nos mais diferentes canais de distribuição, desde feiras livres, lojas especializadas até restaurantes e grandes supermercados. Os canais de distribuição são classificados em venda direta e indireta. Por meio de uma revisão de literatura internacional foi observada uma gama de canais que são acessados pelos produtores de produtos orgânicos. O canal de distribuição direto pode ser interpretado como aquele em que não há nenhum intermediário (CADILHON, 2007). Ou seja, o consumidor compra o produto diretamente do produtor. Assim, classificados como canais diretos, e comumente encontrados no Estados Unidos da América, tem-se: bancas na beira da estrada, compra no estabelecimento rural, feiras livres, feiras dos produtores e Agricultura Suportada pela Comunidade. As características desses canais estão descritas no Quadro 1.

Já no caso da venda indireta, os produtos orgânicos são direcionados aos varejistas e/ou atacadistas. Nesta classificação entram os supermercados, lojas específicas, restaurantes e atacadistas. Neste grupo também estão incluídos os distribuidores, intermediários e a indústrias. O Quadro 2 apresenta uma breve descrição desses canais. 


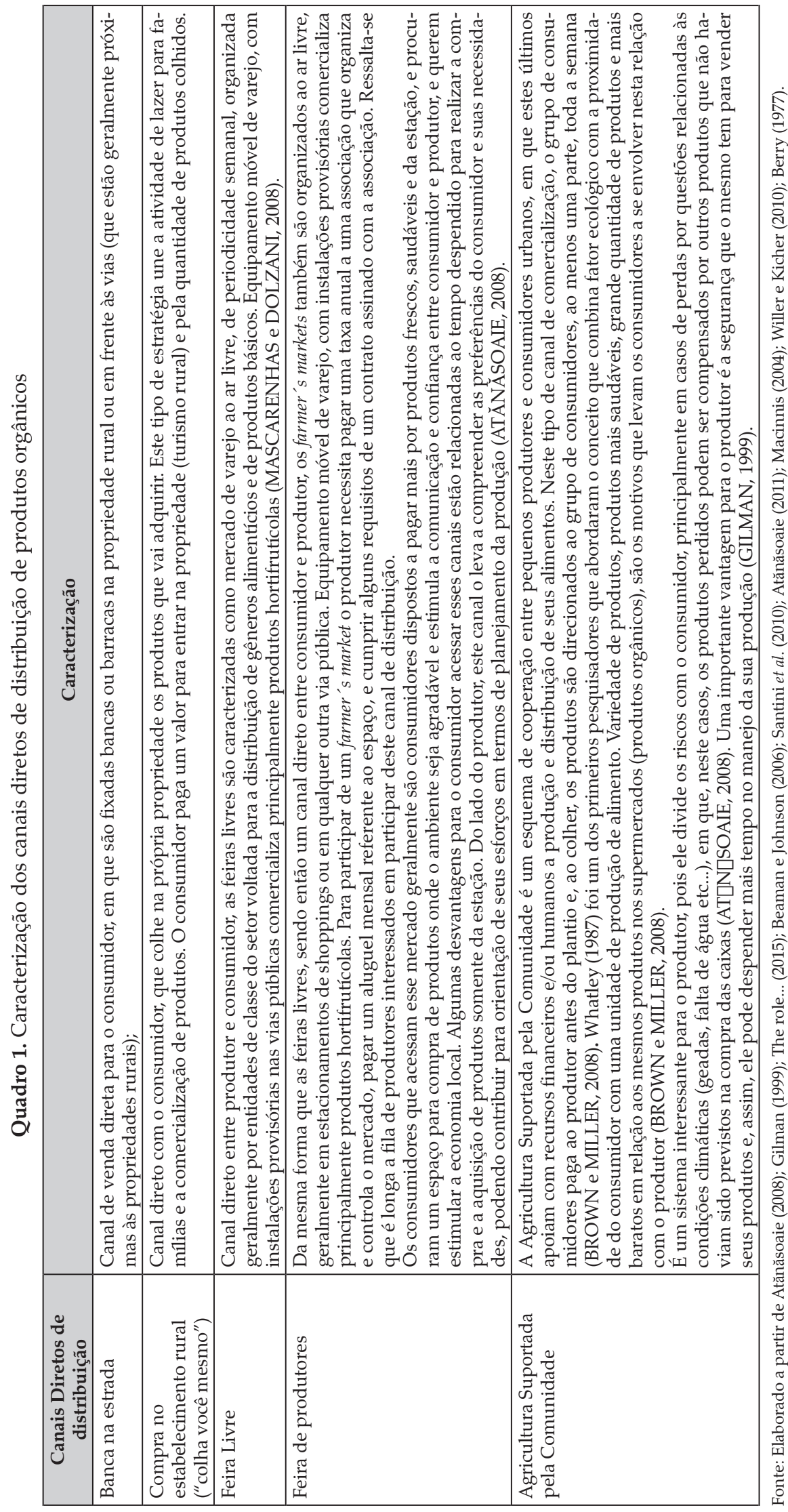




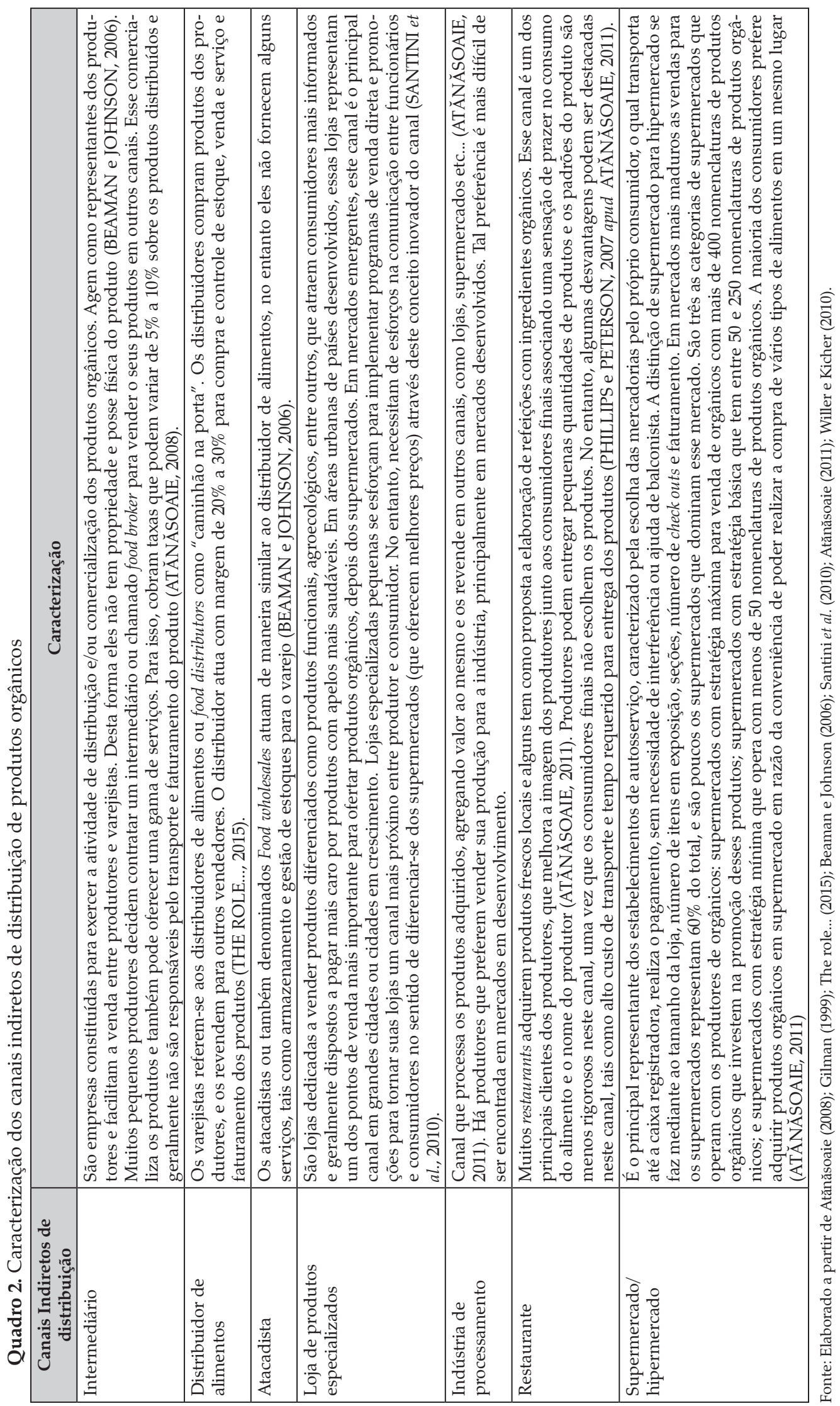


Alguns autores, tais como Brunori e Marescotti (2008), Rossi e Brunori (2010), Bakudila (2013) e Guadagno (2007), argumentam que vem ocorrendo uma mudança no comportamento do consumidor, relacionada mais à questão cultural do que econômica, em aspectos que relacionam "alimento" e "território", uma vez que o consumidor tende a ter uma percepção diferenciada no consumo de produtos alimentares, buscando maior conhecimento com relação ao produto adquirido e até mesmo os meios de produção do alimento. Neste sentido, cresce a importância dos canais chamados "canais curtos", que aproximam o homem (consumidor) do local de produção do alimento, uma vez que diminui a distância entre produção e consumo. Segundo Giuca (2013), a comercialização de produtos em canais curtos promove uma melhoria na renda do produtor, acesso a produtos frescos e proximidade entre produtor e consumidor. Além disso, há vantagens relacionadas à proteção ambiental, tais como: redução do consumo de combustíveis, redução da necessidade de refrigeração dos produtos e no consumo de embalagens (GIUCA, 2013).

Segundo o Censo da agricultura de 2012 do USDA (2014), de maneira geral, não considerando a tipologia de tamanho de propriedade, $63 \%$ dos produtores orgânicos comercializam seus produtos por meio dos atacadistas.

No entanto, ao considerar o tamanho das propriedades, Cantor e Strichilic (2009) realizaram uma pesquisa, por meio de um survey com 103 pequenos e médios produtores (até US\$250,000 de renda) do estado da Califórnia, e constataram que os canais mais comuns eram as vendas diretas, utilizados por $70 \%$ dos produtores, principalmente as feiras de produtores $(62 \%)$. Neste sentido, observa-se que produtores pequenos e médios tendem a priorizar os canais de venda diretos, enquanto os grandes tendem a priorizar os canais de venda indiretos. Há indicações de que este comportamento pode estar relacionado ao grande volume de compras realizado pelo supermercado, limitando os pequenos produtores em razão da escala de produção. Tendo em vista a diminuição dos custos logísticos, os supermercados preferem comprar de grandes produtores que vendem em grandes volumes.

Ainda na classificação proposta (canais de venda direta e indireta) os canais de venda indireta podem ser curtos ou longos. Os canais de venda indireta curtos são aqueles em que há poucas etapas entre produ- tor e consumidor final. Seguindo a lógica proposta por Giuca (2013), o que determina os canais curtos não é apenas a redução da distância entre produtor e consumidor, mas também preferências do consumidor por maior frescor nos produtos e autenticidade. Nesses termos, canais indiretos curtos seriam lojas específicas, restaurantes e alguns tipos de varejistas especializados em produtos frescos. Ou seja, há intermediários entre produtor e consumidor final, mas em menor número.

Segundo MacInnis (2004), a heterogeneidade nas exigências nos mercados diretos e indiretos vai interferir na decisão dos produtores de produtos orgânicos com relação à escolha de qual canal de distribuição mais adequado. Compradores nos mercados diretos valorizam o frescor do produto e a conveniência de compra, e ainda preferem variedade e características de qualidade tais como tamanho, cor, forma e peso. No caso dos mercados diretos, como as feiras de produtores locais, as informações são mais facilmente disponíveis. Os mercados diretos são geralmente concentrados em locais de densidade populacional alta e se torna viável quando os produtores estão próximos a esses locais, uma vez que o custo de transporte para o agricultor para esses locais é frequentemente substancial.

Já os compradores nos mercados indiretos têm preferências distintas em razão da natureza de seus negócios. No modelo de negócios de varejistas e atacadistas as taxas de rentabilidade são altas, e assim eles operam com larga escala de produtos homogêneos e rapidez na entrega dos produtos. Em outras palavras, os grandes mercados preferem grande quantidade e qualidade consistente. Neste modelo de negócios, varejistas e atacadistas realizam suas transações com produtos convencionais, ou orgânicos, ou ambos, por meio de grandes produtores rurais. Desta forma, resta aos pequenos produtores de orgânicos, principalmente de FLV, comercializarem seus produtos em canais de venda direta.

Mundialmente, as grandes redes supermercadistas, uma vez que exercem uma liderança marcante na distribuição de alimentos, forte concentração de capitais e estão mais próximas do consumidor tem importância fundamental na coordenação das cadeias de FLV, dentre outras cadeias agroalimentares. No entanto, ao considerarmos do ponto de vista dos produtores, esses devem ser submetidos às regras impostas nesta relação, que geralmente são mais custosas e difíceis de serem cumpridas sem desvantagens, especificamente 
para os pequenos produtores de forma isolada, diante das fragilidades gerenciais e financeiras, que os impede de atender o mercado com regularidade e volumes constantes (ALCÂNTARA e SOUZA, 2005.

Tais evidências foram reforçadas por Lourenzani e Silva (2010), em pesquisa realizada com pequenos produtores de produtos frescos no Brasil. A pesquisa revelou que uma das dificuldades em acessar determinados canais, como as grandes redes varejistas, refere-se aos atributos requeridos na transação, tais como qualidade, quantidade, diversidade e regularidade. As autoras reforçam que a minimização da diferença entre o que é requerido pelos clientes e o que é oferecido pelos produtores somente é alcançada com investimentos em tecnologia e planejamento da produção.

Neste sentido, segundo Souza, Alcantara (2003) e Alcantara e Souza (2005), cerca de $89 \%$ da produção é escoada por meio de empresas de distribuição do tipo atacadista. As feiras orgânicas, apesar de ainda não serem o principal canal de distribuição de alimentos orgânicos, têm aumentado a sua participação na distribuição dos produtos orgânicos da agricultura familiar e são relevantes, uma vez que produtores podem obter preço até $30 \%$ superior ao dos produtos convencionais.

Estudos também mostram a adoção das chamadas redes de comercialização coletivas para produtores da agricultura familiar. De acordo com Brito (1999) as "redes de firmas" são arranjos cooperativos e sistemáticos entre organizações que são formalmente independentes. Essas redes seriam fundamentais para aumentar o acesso de produtores da agricultura familiar aos mercados e, além disso, podem promover o intercâmbio de experiências e a promoção de produtos da agricultura familiar (SEPULCRI e TRENTO, 2009). Outro conceito estabelecido na literatura é o de ações coletivas, que seria mais amplo comparado com as redes, e um dos principais objetivos seria sua formação para acesso aos mercados. Conceito semelhante é apresentado por Lourenzani e Silva (2006), com as ações coletivas entre produtores rurais com o objetivo de comercialização. As ações coletivas se justificam em razão da exclusão de pequenos produtores do mercado e as mudanças nos padrões de competição dominado por grandes varejistas (MACHADO, 2004). Além disso, quando organizados em grupos, os pequenos produtores mitigam as dificuldades encontradas para o investimento em tecnologia e planejamento da produção, uma vez que os custos são diluídos entre os membros do grupo (LOURENZANI e SILVA, 2010).

Um estudo realizado nos estados do Paraná, Santa Catarina e São Paulo observou que as associações são relevantes para os produtores de orgânicos em suas regiões, sejam eles diretamente associados, contratados, independentes ou parceiros de associações que distribuem e/ou beneficiam os produtos orgânicos. Essas organizações são relevantes para os produtores não somente em relação à distribuição de seus produtos, mas também em razão do oferecimento de serviços de assistência técnica, planejamento da produção e remuneração pela qualidade do produto fornecido (ALCÂNTARA e SOUZA, 2005).

No entanto, mesmo vinculados a uma associação, a relação comercial com grandes empresas do varejo ainda necessita ser mitigada. Em um estudo realizado na Rede Ecovida, que faz articulações técnicas e de acesso aos mercados para grupos de pequenos produtores de orgânicos, organizados em associações ou cooperativas, ressalta as resistências dos supermercados na distribuição de seus produtos. São impostas restrições quanto à padronização dos produtos, muitas vezes não alcançadas pelos produtores e, além disso, a remuneração dos produtores é referente somente àquilo que vendem. No entanto, seus produtos acabam acessando os grandes mercados, via empresas processadoras com marcas já consolidadas no mercado com selo orgânico, ou mesmo distribuidores sem uso de contratos (NIEDERLE e RAULET, 2014; COSTA, 2005).

Neste sentido, tem-se uma diferença entre o acesso dos produtores de orgânicos brasileiros nos supermercados se comparados com os americanos. Em razão do maior consumo desses produtos no mercado americano, as redes de supermercado se relacionam com os produtores de orgânicos, ou distribuidores, por meio de contratos, sejam eles informais ou formais, a fim de garantir a regularidade na oferta dos produtos. São muitas as vantagens associadas nestas transações: garantia de venda do produto, regularidade nas transações a longo prazo, descontos financeiros na nota fiscal menores se comparados ao Brasil e promoção do produto por parte do supermercado (CUNHA, SAES e MAINVILLE, 2013). No entanto, da mesma forma que ocorre no Brasil, nos Estados Unidos os supermercados dão prioridade a transações comerciais com grandes produtores em detrimento aos pequenos e médios produtores. 
Segundo o relatório do USDA (2009), para que pequenos e médios produtores de orgânicos possam melhor se inserir no mercado é fundamental trabalhar em rede e acessar o mercado por meio de cooperativas de comercialização, centros de distribuição e sympathetic distributions, como a agricultura suportada pela comunidade. Tais canais promovem o que denomina-se value-based distribution chain (cadeias de distribuição baseada no valor), que distinguem-se das correntes tradicionais de abastecimento de alimentos pela combinação de como eles operam com parcerias estratégicas (relações comerciais) e como eles diferenciam seus produtos (com foco em qualidade e atributos ambientais e sociais) (DUPUIS, 2006).

No entanto, algumas pesquisas colocam em "xeque" mecanismos de comercialização direta, como é o caso da agricultura apoiada pela comunidade. Brown e Miller (2008) citam alguns estudos que podem levantar dúvidas com respeito às melhores condições de remuneração do produtor inserido neste canal de distribuição. Um estudo canadense observou que, na divisão dos preços, o produtor recebia somente o suficiente para cobrir os custos operacionais e pequena parte dos custos relativos a taxas, seguro e moradia, resultando em zero retorno para o trabalho da família na propriedade. Segundo este estudo, os produtores recebiam US\$ 180.00 e deveriam receber, para cobrir todos os custos, US\$ 414.15. No Meio-Oeste americano, pequenos produtores que participam desse canal consideram que o preço pago não é justo, mas estão satisfeitos com esse mecanismo pois proporcionou melhoria na qualidade de vida.

Em um estudo sobre renda de produtores de vegetais frescos no nordeste do Vietnã, Wang, Moustier e Loc (2014) observaram que a utilização de canais diretos aumenta a renda dos produtores. Os autores argumentam que os canais diretos aumentam os benefícios para os produtores em função do maior acesso aos mercados. O maior acesso permite que os produtores entendam melhor as preferências do consumidor e, desta maneira, possam capturar maior valor ao comercializar seus produtos por meio deste canal.
Tais evidências são reforçadas em outras pesquisas como Blum (2001), Araújo (2005), Kambara e Shelley (2002). Segundo os autores, a comercialização via venda direta proporciona melhor rentabilidade aos pequenos agricultores, visto a eliminação de empresas intermediárias.

Tendo em vista o argumento apresentado, o objetivo deste artigo é investigar se os pequenos produtores priorizam o acesso a canais de venda direta. Para tal, foi feita uma pesquisa empírica com produtores de frutas e vegetais orgânicos no estado da Califórnia. A pesquisa e seus resultados são apresentados na seção seguinte.

\section{Material e métodos}

A coleta de dados foi realizada entre janeiro e março de 2015 por meio de formulários enviados por e-mail a 1.383 produtores orgânicos do estado da Califórnia (EUA), considerando as culturas mais representativas do estado (frutas, legumes, verduras e nozes), cadastrados no banco de dados do USDA em 2014. Os formulários foram enviados neste período (de três meses) uma vez por semana. Desse universo, obteve-se o retorno de 70 questionários (5\%), sendo que 60 foram validados. Ressalta-se também que foi aplicado o questionário com seis produtores por meio de entrevista presencial, sendo possível obter melhor percepção dos produtores a respeito do assunto pesquisado. A seguir, segue uma descrição dos dados coletados.

O estado da Califórnia é dividido em 58 counties, e a amostra da pesquisa está distribuída em 27 dos 58 counties, uma vez que produtores destes counties responderam o questionário. Em relação ao principal canal de venda utilizado pelos produtores de orgâni$\cos$ (Tabela 1), a maioria utiliza atacadistas $(28,33 \%)$, seguido dos supermercados (15\%), sendo ambos considerados canais indiretos de venda. Um canal de venda direto aparece apenas como terceira opção mais utilizada, feira de produtores $(11,67 \%)$, junto a distribuidor de alimentos ou intermediário, também com 11,67\%, ambos canais indiretos. 
Tabela 1. Canal de venda mais importante indicado pelos produtores

\begin{tabular}{llc}
\hline \multicolumn{1}{c}{ Canal de distribuição } & Frequência \\
\hline & \multicolumn{1}{c}{ Indireto } & $28,33 \%$ \\
& Atacadista & $15,00 \%$ \\
Feira do produtor & Supermercado & $11,67 \%$ \\
& Distribuidor de Alimentos & $11,67 \%$ \\
& & $11,67 \%$ \\
& Intermediário & $6,67 \%$ \\
Feira livre & Loja especializada & $6,67 \%$ \\
Amigos & Restaurante & $5,00 \%$ \\
\hline
\end{tabular}

Fonte: Elaborado pelos autores.

Os produtores foram questionados a respeito da renda obtida em 2014, sendo que $40 \%$ dos produtores declararam ter rendimento de até US\$49.000, sendo os demais distribuídos conforme a Tabela 2. Ao considerar a classificação do Quadro 1, os canais de distribuição foram agrupados em "Canais Diretos" e "Canais Indiretos", sendo que $15 \%$ dos produtores declaram ter um canal direto como principal canal de venda, e os demais, $85 \%$ dos produtores, declaram ter um canal indireto como principal canal de venda (Tabela 2).

O USDA utiliza o Grass Cash Farm Income (GCFI) para determinar o tamanho das propriedades rurais. Também é utilizado para explicar a distribuição dos impactos políticos, de mercado e desenvolvimento tecnológico. Sendo assim, esse trabalho partiu da classificação original de propriedades rurais segundo a renda (HOPPE e MACDONALD, 2013):

- Fazendas não comerciais: GCFI menor que US\$10,000
- Pequenas fazendas comerciais: GCFI entre US\$10,000 e US\$249,999

- Grandes fazendas: GCFI entre US\$250,000 e US\$ 999,999

- Fazendas muito grandes: GCFI de US\$ 1 milhão ou mais

Desta maneira, consideraremos como pequenas as propriedades com rendas até US\$249,999; em contrapartida, as grandes propriedades são aquelas com rendas superiores a US\$250,000. A análise por meio da variável renda é relevante para determinar o tamanho da propriedade e, assim, classificar pequenas e grandes propriedades.

\subsection{Análise estatística}

Anterior à execução da análise estatística, um teste de pressupostos básicos é normalmente realizado para

Tabela 2. Tabela cruzada entre renda dos produtores, e principal canal de venda utilizado

\begin{tabular}{lccc}
\hline \multicolumn{1}{c}{$\begin{array}{c}\text { Faixas de renda } \\
\text { dos produtores }\end{array}$} & \multicolumn{2}{c}{ Canais de venda } & \multirow{2}{*}{ Total geral } \\
\cline { 2 - 3 } & (1) Canal direto & (2) Canal indireto & \\
\hline (1) até 49,999 & 5 & 19 & 24 \\
(2) $50,000-99,999$ & 2 & 6 & 8 \\
(3) $100,000-149,999$ & 1 & 5 & 6 \\
(4) $150,000-199,999$ & 1 & 4 & 5 \\
(5) $200,000-249,999$ & 0 & 3 & 3 \\
(6) $250,000-499,999$ & 0 & 2 & 2 \\
(7) mais do que 499,999 & 0 & 12 & 12 \\
Total & 9 & 51 & 60 \\
\hline
\end{tabular}

${ }^{1}$ Valores em dólares americanos referentes a 2014.

Fonte: Elaborado pelos autores. 
determinar quais métodos estatísticos são adequados para a análise dos dados coletados (FONSECA e GABRIEL, 2015; HSU e CHEN, 2015). Após a codificação dos dados obtidos nos questionários, os dados foram analisados com o software Statistical Package for the Social Sciences (SPSS ${ }^{\circledast}$ ) versão 18 e o Stata ${ }^{\circledR}$ versão 11.2. Inicialmente buscou-se verificar a normalidade dos dados por meio dos testes de normalidade Kolmogorov-Smirnov e Shapiro-Wilk. Para ambos os testes (resultados apresentados na Tabela 3), os dados dos canais diretos de distribuição e canais indiretos de distribuição não estão distribuídos normalmente (Sig. < 0,05). A normalidade de todos os itens não é atingida; portanto, o teste $\mathrm{t}$ não pode ser aplicado para o teste de hipótese, sem viés potencial. Assim, testes estatísticos não paramétricos são usados para testar hipóteses. Essa situação determinou a escolha do teste de Mann-Whitney para o entendimento da relação entre os canais de vendas e a renda dos produtores de orgânicos.

O teste de Mann-Whitney é usado para comparar as diferenças entre os dois grupos independentes quando a variável dependente é ordinal ou contínua, mas que não são normalmente distribuídas (HART, 2001).

Para avaliar se a renda dos produtores de orgânicos difere de acordo com o tipo de canal de distribuição adotado, elaborou-se a seguinte hipótese nula $\left(\mathrm{H}_{0}\right)$ : "não existe diferença estatisticamente significante entre a renda dos produtores de orgânicos que utilizam canal de venda direta e produtores que utilizam canal de venda indireta". A hipótese alternativa $\left(\mathrm{H}_{1}\right)$ que segue é a de que "existe diferença estatisticamente significante entre a renda dos produtores de orgânicos que utilizam canal de venda direta e produtores que utilizam canal de venda indireta".

Além do teste de Mann-Whitney foi realizado o teste $\mathrm{H}$ de Kruskal-Wallis. Esse teste é usado para comparar as diferenças estatisticamente significativas entre os dois ou mais grupos independentes quando a variável dependente é ordinal ou contínua, mas que não são normalmente distribuídas (FIELD, 2009). É considerada uma alternativa não paramétrica para a ANOVA unidirecional e uma extensão do teste $U$ de Mann-Whitney para permitir a comparação de mais de dois grupos independentes. Neste sentido, para complementar a análise pelo teste de Mann-Whitney, o teste $\mathrm{H}$ de Kruskal-Wallis foi considerando, realizando duas análises em que as variáveis dependentes foram a renda e o tamanho da propriedade, e as variáveis independentes, os tipos de canais diretos e indiretos.

\section{Resultado e discussão}

O teste de Mann-Whitney foi utilizado para verificar a diferença entre o canal direto (produtores que utilizam canais diretos como principal canal para distribuição de seus produtos) e canal indireto (produtores que utilizam canais indiretos como principal canal para distribuição de seus produtos) em relação à renda desses produtores referente a 2014. O nível de significância usado é de $\mathrm{p}<0,05$, sendo os dados computados também no SPSS 18.

Inicialmente verificou-se que as distribuições dos scores de renda para canal indireto e canal direto foram semelhantes, avaliada pela inspeção visual. O resumo do resultado estatístico de Mann-Whitney discriminado para a variável dependente está apresentado na Tabela 4. A comparação dos dois grupos, por meio do teste de Mann-Whitney, apresentou um Asymp. Sig. (2-tailed) $p=0,091$, que significa que o resultado não é estatisticamente significante e, assim, não se pode rejeitar a hipótese nula. Isto acontece pois $p$-value $>$ 0,05 . Portanto, a falta de significância estatística ( $\mathrm{p}=$ 0,091 ) indica que não existem diferenças estatisticamente significantes entre a renda dos grupos canal direto e canal indireto.

Tabela 3. Teste de normalidade

\begin{tabular}{|c|c|c|c|c|c|c|c|c|}
\hline & \multirow{2}{*}{\multicolumn{2}{|c|}{$\begin{array}{c}\text { Canal de } \\
\text { distribuição }\end{array}$}} & \multicolumn{3}{|c|}{ Kolmogorov-Smirnov* } & \multicolumn{3}{|c|}{ Shapiro-Wilk } \\
\hline & & & $d f$ & Sig. & Estatística & $g l$ & Sig. & Estatística \\
\hline \multirow{2}{*}{ Renda } & \multirow{2}{*}{ Dimensão } & 1 & ,317 & 9 & ,009 & ,767 & 9 & ,009 \\
\hline & & 2 & 208 & 51 & ,000 & ,801 & 51 & ,000 \\
\hline
\end{tabular}

* Lilliefors Significance Correction.

Fonte: Elaborado pelos autores. 
Tabela 4. Resultado do teste de Mann-Whitney

\begin{tabular}{lc}
\hline \multicolumn{1}{c}{ Estatísticas de teste } & Renda \\
\hline Mann-Whitney U & 151,000 \\
Wilcoxon W & 196,000 \\
Z & $-1,691$ \\
Asymp. Sig. (2-tailed) &, 091 \\
\hline
\end{tabular}

*Variável de agrupamento: Canal de distribuição Fonte: Elaborado pelos autores.

A Tabela 5 mostra que a mediana da renda para o grupo canal indireto foi 3,00, sendo maior do que o grupo canal direto, que apresentou valor mediano de 1,00 . No entanto, como já dito, estas medianas não têm diferenças estatisticamente significantes. Da mesma forma, a média gerada pelos postos do canal direto é mais elevado; no entanto, ela não se mostrou significante estatisticamente.

Tabela 5. Caracterização dos grupos em relação à mediana, média dos postos e somas dos postos

\begin{tabular}{lcccc}
\hline \multirow{2}{*}{$\begin{array}{c}\text { Canal de } \\
\text { distribuição }\end{array}$} & $n$ & Mediana & $\begin{array}{c}\text { Média dos } \\
\text { postos }\end{array}$ & $\begin{array}{c}\text { Soma dos } \\
\text { postos }\end{array}$ \\
\cline { 2 - 5 } & 9 & 1,00 & 21,78 & 196,00 \\
(1) Canal direto & 51 & 3,00 & 32,04 & 1634,00 \\
(2) Canal indireto & 51 & - & - \\
Total & 60 & 2,00 & - & \\
\hline
\end{tabular}

Fonte: Elaborado pelos autores.

Sabe-se que o tamanho das propriedades nos EUA é determinado segundo a renda da propriedade. Neste sentido, uma propriedade cuja renda máxima anual é de US\$ 249.999 é considerada pequena; já uma propriedade acima desta renda é considerada grande. No entanto, de forma complementar, buscou-se caracterizar o tamanho das propriedades por meio de sua área medidas em acres (Tabela 6). O que se percebe é que a maioria das propriedades (56\%) tem até 50 acres de áreas.

Tabela 6. Área da propriedade (em acres)

\begin{tabular}{lc}
\hline \multicolumn{1}{c}{ Área } & Total \\
\hline $0-9$ & 13 \\
$10-49$ & 21 \\
$50-79$ & 2 \\
$80-179$ & 6 \\
$180-499$ & 9 \\
Mais que 500 acres & 9 \\
Total Geral & 60 \\
\hline
\end{tabular}

Fonte: Elaborado pelos autores.
Com o intuito de entender quais canais são prioritariamente utilizados pelos pequenos produtores de orgânicos, por meio de uma análise descritiva dos dados é possível constatar que a maioria dos produtores ditos pequenos utiliza canais indiretos, constituindo $80 \%$ dos pequenos produtores (Tabela 7). Contudo, não é possível verificar se essas proporções apresentam diferenças estaticamente significantes, pois os dados não são normalmente distribuídos. Esse fato contraria a literatura, que relaciona pequenos produtores a canais diretos de venda.

Tabela 7. Canais de venda priorizados em relação as faixas de renda dos produtores de orgânico

\begin{tabular}{lccc}
\hline \multicolumn{1}{c}{ Renda (ano 2014) } & $\begin{array}{c}\text { Canal } \\
\text { direto }\end{array}$ & $\begin{array}{c}\text { Canal } \\
\text { indireto }\end{array}$ & $\begin{array}{c}\text { Total } \\
\text { geral }\end{array}$ \\
\hline (1) $0-49.999$ & 5 & 19 & 24 \\
(2) $50.000-99.999$ & 2 & 6 & 8 \\
(3) $100.000-149.999$ & 1 & 5 & 6 \\
(4) $150.000-199.999$ & 1 & 4 & 5 \\
(5) $200.000-249.999$ & 0 & 3 & 3 \\
Total & $9(20 \%)$ & $37(80 \%)$ & 46 \\
\hline
\end{tabular}

Fonte: Elaborado pelos autores.

Em relação aos produtores caracterizados como grandes (renda em 2014 superior a US\$ 250.000), a pesquisa realizada aponta predominância na prioridade dada a utilização de canais indiretos de venda, como supermercados e distribuidores, conforme mostra a Tabela 8. Neste caso, os resultados obtidos corroboram os estudos de Wang, Moustier, \& Loc (2014), Giuca (2013) e USDA (2009).

Tabela 8. Canais de venda priorizados em relação as faixas de renda dos produtores de orgânico

\begin{tabular}{lccc}
\hline \multicolumn{1}{c}{ Renda (ano 2014) } & $\begin{array}{c}\text { Canal } \\
\text { direto }\end{array}$ & $\begin{array}{c}\text { Canal } \\
\text { indireto }\end{array}$ & $\begin{array}{c}\text { Total } \\
\text { geral }\end{array}$ \\
\hline (6) 250.000 - 499.999 & 0 & 2 & 2 \\
(7) maior que 499.999 & 0 & 12 & 12 \\
Total & $0(0 \%)$ & $14(100 \%)$ & 14 \\
\hline
\end{tabular}

Fonte: Elaborado pelos autores.

Com o intuito de aprofundar a análise, utilizou-se apenas a amostra de produtores de orgânicos nas faixas de renda que caracterizam produtores de pequeno porte (renda em 2014 de até US\$249,999), em que buscou-se entender se a renda difere de acordo com o tipo de canal de distribuição adotado. Dessa forma, pre- 
tende-se verificar se o canal utilizado traz diferenças para a renda de produtores de orgânicos de pequeno porte. A partir do problema colocado, formula-se a seguinte hipótese nula $\left(\mathrm{H}_{0}\right)$ : não existe diferença estatisticamente significante entre a renda de 2014 dos pequenos produtores de orgânicos que utilizam canal direto de venda e dos pequenos produtores que utilizam canal indireto de vendas. A hipótese alternativa $\left(\mathrm{H}_{1}\right)$ é: existe diferença estatisticamente significante entre a renda de 2014 dos pequenos produtores de orgânicos que utilizam canal direto de venda e dos pequenos produtores que utilizam canal indireto de vendas. O nível de significância usado é de $\mathrm{p}<0.05$.

A comparação dos dois grupos, através do teste $\mathrm{U}$ Mann-Whitney (Tabela 9), apresentou um Asymp. Sig. (2-tailed) $p=0,641$, que significa que o resultado não é estatisticamente significante e, assim, não se pode rejeitar a hipótese nula, isto porque $p$-value $>0,05$. Portanto, a falta de significância estatística indica que não existem diferenças estatisticamente significantes entre a renda dos grupos canal direto e canal indireto. Ou seja, nenhum dos canais gera maiores rendas para os pequenos produtores de orgânicos.

Tabela 9. Resultado do teste de Mann-Whitney

\begin{tabular}{lc}
\multicolumn{1}{c}{ Estatísticas do teste* $^{*}$} & Renda \\
\hline Mann-Whitney U & 151,000 \\
Wilcoxon W & 196,000 \\
Z &,- 466 \\
Asymp. Sig. (2-tailed) &, 641 \\
\hline
\end{tabular}

* Variável de agrupamento: Canal de distribuição.

Fonte: Elaborado pelos autores.

A Tabela 10 mostra que a mediana da renda para o grupo canal indireto foi 1,00, sendo igual à mediana do grupo canal direto. Já em relação à média dos postos, $\mathrm{o}$ canal direto apresenta maior média; contudo, ela não se mostra estatisticamente significante.

Tabela 10. Caracterização dos grupos em relação à mediana, média dos postos e somas dos postos

\begin{tabular}{lcccc}
\hline \multirow{2}{*}{$\begin{array}{c}\text { Canal de } \\
\text { distribuição }\end{array}$} & $n$ & Mediana & $\begin{array}{c}\text { Média dos } \\
\text { postos }\end{array}$ & $\begin{array}{c}\text { Soma dos } \\
\text { postos }\end{array}$ \\
\cline { 2 - 5 } & 9 & 1,00 & 18,06 & 162,50 \\
\hline (1) Canal direto & 93 & 1,00 & 22,44 & 740,50 \\
(2) Canal indireto & 33 & - & - \\
Total & 42 & 1,00 & - &
\end{tabular}

Fonte: Elaborado pelos autores.
Há de ressaltar que, dos pequenos produtores, apenas metade deles está vinculada a alguma associação ou cooperativa. No caso dos grandes produtores, $40 \%$ estão vinculados a alguma organização associativa. E ainda observou-se, entre 2012 e 2013, um aumento na participação dos pequenos produtores em associações ou cooperativas (em 13\%), enquanto entre os grandes produtores houve redução de $33,33 \%$. Dos pequenos produtores que estão inseridos em alguma organização associativista, $86 \%$ estão vinculados a associações ou cooperativas em razão do acesso ao mercado e/ou negociações de venda por preços melhores. Dos grandes produtores, metade está vinculada a uma associação ou cooperativa em razão da negociação de venda dos produtos com melhores preços.

Para complementar e aprofundar as análises realizadas, foram realizadas as análises pelo teste $\mathrm{H}$ de Kruskal-Wallis considerando os "tipos de canais e a renda", bem como os "tipos de canais e o tamanho das propriedades".

Para entender se a renda dos produtores de orgânicos (em que a variável dependente seria renda, medidas em uma escala ordinal) difere de acordo com o tipo de canal de distribuição adotado (a variável independente seria o tipo de canal de distribuição, sendo considerados cinco tipos de canais: feira dos produtores, intermediário, distribuidor de alimentos, supermercado e atacadista. Feira de produtos é considerado "Canal Direto" e os demais "Canal Indireto"). Foram considerados na análise esses cinco canais, uma vez que mais de $75 \%$ dos produtores indicaram que priorizam as suas vendas nesses canais.

A partir do problema colocado, formulam-se as seguintes hipóteses: $\mathrm{H}_{0:}$ sem diferença estatisticamente significante nas medianas da renda entre os grupos de feiras de produtores, intermediário, distribuidor de alimentos, supermercado e atacadista (ou seja, não existem diferenças estatisticamente significantes entre renda dos cinco grupos. $\mathrm{H}_{1}$ : existe diferença estatisticamente significante nas medianas da renda entre os grupos de feiras de produtores, intermediário, distribuidor de alimentos, supermercado e atacadista (ou seja, a renda de um grupo é superior à renda do outro grupo).

O nível de significância usado é de $\mathrm{p}<0.05$. A Tabela 11 apresenta uma descrição da amostra em que foi testado se a renda era diferente para os produtores que utilizam cinco tipos de canal de vendas: (a) feira de 
produtores $(\mathrm{n}=7)$; $(\mathrm{b})$ intermediário $(\mathrm{n}=7)$; $(\mathrm{b})$ distribuidor de alimentos $(\mathrm{n}=7)$; $(\mathrm{d})$ supermercado $(\mathrm{n}=9)$; e (e) atacadista $(n=17)$.

Tabela 11. Descrição das amostras

\begin{tabular}{lcc}
\hline \multicolumn{1}{c}{ Canal } & Observações & $\begin{array}{c}\text { Soma da } \\
\text { pontuação }\end{array}$ \\
\hline Feira de produtores & 7 & 104,00 \\
Intermediário & 7 & 223,50 \\
Distribuidor de alimentos & 7 & 149,00 \\
Supermercado/hipermercado & 9 & 208,00 \\
Atacadista & 17 & 443,50 \\
\hline
\end{tabular}

Fonte: Elaborado pelos autores.

A comparação dos grupos, por meio do teste $\mathrm{H}$ de Kruskal-Wallis, apresentou um $\chi 2=6,16$ e $\mathrm{p}=0,1875$, os quais significam que o resultado não é estatisticamente significante e, assim, não se pode rejeitar a hipótese nula, isto porque $p$-value $>0,05$. Portanto, a falta de significância estatística ( $\mathrm{p}=0,1875)$ indica que não existem diferenças estatisticamente significantes entre a renda dos que utilizam os cinco diferentes canais de venda.

Em um segundo momento, utilizou-se o teste $\mathrm{H}$ de Kruskal-Wallis para entender se o tamanho da propriedade dos produtores de orgânicos (em que a variável dependente seria tamanho da propriedade, medida em uma escala ordinal por meio da área das propriedades em acres) diferem de acordo com o tipo de canal de distribuição adotado (a variável independente variável seria tipo de canal de distribuição, sendo considerados cinco tipos de canais: feiras de produtores, intermediário, distribuidor de alimentos, supermercado e atacadista. Feira dos produtores é considerado "Canal Direto" e os demais, "Canal Indireto").

A partir do problema colocado, formulam-se as seguintes hipóteses: $\mathrm{H}_{0}$ : sem diferença estatisticamente significante nas medianas do tamanho da propriedade entre os grupos feira de produtores, intermediário, distribuidor de alimentos, supermercado e atacadista (ou seja, não existem diferenças estatisticamente significantes entre do tamanho da propriedade dos cinco grupos). $\mathrm{H}_{1}$ : existe diferença estatisticamente significante nas medianas do tamanho da propriedade entre os grupos feira de produtores, intermediário, distribuidor de alimentos, supermercado e atacadista (ou seja, o tamanho da propriedade de pelo menos um dos grupo é superior ao tamanho da propriedade dos demais).
O nível de significância usado é de $p<0.05$. A Tabela 12 apresenta uma descrição da amostra em que foi testado se a renda era diferente para os produtores que utilizam cinco tipos de canal de vendas: (a) feira de produtores $(\mathrm{n}=7)$; $(\mathrm{b})$ intermediário $(\mathrm{n}=7)$; $(\mathrm{b})$ distribuidor de alimentos $(\mathrm{n}=7)$; $(\mathrm{d})$ supermercado $(\mathrm{n}=9)$; e (e) intermediário $(\mathrm{n}=17)$.

Tabela 12. Descrição das amostras

\begin{tabular}{lcc}
\hline \multicolumn{1}{c}{ Canal } & Observações & $\begin{array}{c}\text { Soma da } \\
\text { pontuação }\end{array}$ \\
\hline Feira de produtores & 7 & 119,50 \\
Intermediário & 7 & 193,50 \\
Distribuidor de alimentos & 7 & 149,00 \\
Supermercado/hipermercado & 9 & 167,50 \\
Atacadista & 17 & 498,50 \\
\hline
\end{tabular}

Fonte: Elaborado pelos autores.

A comparação dos grupos, através do teste $\mathrm{H}$ de Kruskal-Wallis, apresentou um $\chi 2=6,509$ e $p=0,1642$, que significam que o resultado não é estatisticamente significante e, assim, não se pode rejeitar a hipótese nula, isto porque $p$-value $>0,05$. Portanto, a falta de significância estatística ( $p=0,1642$ ) indica que não existem diferenças estatisticamente significantes entre o tamanho da propriedade entre os produtores que utilizam os cinco diferentes canais de venda.

Neste sentido, este estudo vem conflitar com percepções de estudos já realizados como Wang, Moustier e Loc (2014), Giuca (2013), Cantor e Strichilic (2009), USDA (2014), entre outros, pois não é o fato de ser uma pequena propriedade que esta prioriza os canais diretos de distribuição, como feiras de produtores, bancas na beira da estrada, entre outros. O estudo apontou que o fato de uma propriedade ser de pequeno porte não determina as prioridades em termos de acesso aos canais, sejam eles diretos ou indiretos, nem ao menos o tipo de canal dentro das categorias direto ou indireto. Uma das razões que podem justificar a não priorização dos canais diretos pelo pequeno produtor deve-se ao fato de que alguns produtores acessam o mercado por meio de intermediários em razão do esforço significativo na comercialização via canal direto, que demandaria maior tempo do produtor. Este foi um dos motivos percebidos na coleta de dados realizada presencialmente. Além disso, por meio de intermediários, tais produtores não necessitam despender esforços e investimentos em promoção do produto e podem 
estabelecer uma relação de longo prazo, que significa maior garantia da venda do produto se comparada com a venda direta (CUNHA, SAES e MAINVILLE, 20013). Já com relação aos grandes produtores, esses tenderiam a comercializar seus produtos em canais indiretos, em razão da produção em escala que levaria a maiores esforços de comercialização, se optassem a utilizar canais diretos. No entanto, vale ressaltar que a região onde os dados foram coletados é onde os canais de venda direta são relevantes, tais como as feiras de produtores. Neste sentido, é um canal alternativo atrativo também para os grandes produtores em razão dos melhores preços praticados.

\section{Considerações finais}

Esta pesquisa teve como pressuposto que os produtores pequenos priorizariam os canais diretos. De acordo com a literatura, os pequenos produtores de orgânicos optariam por canais diretos de distribuição em razão da eficiência econômica, com melhoria na renda do produtor. Para classificação dos tamanhos das propriedades, atrelou-se a renda do produtor, considerando a classificação para tamanho da propriedade com relação à renda do produtor, conforme critérios do USDA.

O teste de Mann-Whitney U foi executado para determinar se haviam diferenças na renda entre produtores de orgânicos que utilizam Canais Diretos e Canais Indiretos como principal canal de distribuição para seus produtos. A mediana de renda entre canal indireto $(3,00)$ e canal direto $(1,00)$ não teve diferença estatisticamente significante, $U=151, z=-1,691$, $p=0,091$, concluindo que não existem diferenças estatisticamente significantes entre a renda dos grupos "canal direto" e "canal indireto". Além disso, fazendo uma análise para verificar se existe diferença estatisticamente significante entre a renda de 2014 dos pequenos produtores de orgânicos que utilizam canal direto de venda e dos pequenos produtores que utilizam canal indireto de vendas, a mediana da renda dos pequenos produtores tanto para o canal direto como para o canal indireto é igual, e não teve diferença estatisticamente significante, $U=151, z=-0,0466, p=0,641$.

Por meio do aprofundamento das análises relacionando renda com os tipos de canais, além do tamanho e tipos de canais, os resultados também mostraram que a escolha dos tipos de canais, dentro das categorias de canais diretos e indiretos, também não está relacionada à renda, nem tampouco ao tamanho da propriedade.

Desta maneira, este trabalho concluiu que, apesar de as referências apontarem a priorização de canais diretos por parte dos produtores pequenos, a opção dos canais de distribuição, sejam eles diretos ou indiretos, não estão atreladas à renda do produtor, seja ele pequeno ou grande, uma vez que os pequenos produtores não priorizam ambos os canais (diretos e indiretos).

Pode-se supor, diante das percepções levantadas na pesquisa, que a escolha do canal adequado esteja mais relacionada às motivações do produtor rural, em relação à qualidade de vida e perspectivas de crescimento do seu negócio, uma vez que tais perspectivas podem influenciar na decisão de quais canais devam acessar. Além disso, o fato de os canais diretos demandarem volume maior de atividades desenvolvidas diretamente pelos produtores para viabilizar a distribuição de seus produtos, muitos optam pelos canais indiretos, uma vez que não demandam tais esforços. Ressalta-se também a grande participação dos produtores em associações ou cooperativas a fim de acessar mercados. Conforme observado tanto na literatura nacional quanto internacional, essas organizações são relevantes para os produtores no acesso aos mercados, visto que isoladamente não conseguem atender às demandas das grandes redes varejistas. Segue-se ainda que, comercializando seus produtos por meio de intermediários, distribuidores de alimentos ou atacadistas, há segurança maior de venda dos produtos, em razão do compromisso firmado entre ambos, via contrato formal ou informal. Por fim, o produtor pode optar trabalhar com mais de um canal simultaneamente, de maneira a diversificar seus pontos de distribuição e diminuir os riscos da atividade.

Para trabalhos futuros, sugere-se que seja realizado um estudo que busque identificar tais motivações e perspectivas de acesso a canais diretos e indiretos.

\section{Referências}

ALCANTARA, R. L. C. e SOUZA, A. P. O. Alternativas de mercado para a agricultura: a realidade dos produtos hortícolas orgânicos no Brasil. In: BATALHA, M. O. (Org.). Gestão do agronegócio: textos selecionados. São Carlos: EDUFSCAR, 2005, v. 1, p. 261-306. 
ARAÚJO, M. J. Fundamentos de agronegócio. 2. ed. São Paulo: Atlas, 2005.

ATĂNĂSOAIE, G. Distribution channels on the organic foods market. Journal of Horticulture. Forestry and Biotechnology, v. 15, n. 3, p. 19-25, 2011.

BAKUDILA, A. The consumer as "co-producer". In: GIARE, F.; GIUCA, S. (Eds.). Farmers and short chain: legal profles and socio-economic dynamics. Roma: INEA, 2013. p. 121-127.

BEAMAN, J. A. e JOHNSON, A. J. A guide for new manufactures - Grocery retailers in the northwest, 2006. Disponível em: <http://ir.library.oregonstate. edu/xmlui/bitstream/handle/1957/20442/em8924.pdf>.

BLUM, R. Agricultura familiar: estudo preliminar da definição, classificação e problemática. In: TEDESCO, J. C. (Org.). Agricultura familiar realidades e perspectivas. 3. ed. Passo Fundo: UPF, 2001. p. 57-104.

BRITTO, J. N. de P. Características estruturais e modusoperandi das redes de firmas em condições de diversidade tecnológica. Tese (Doutorado) - UFRJ. Rio de Janeiro, 2009.

BROWN, C. e MILLER, S. The impacts of local markets: A review of research on farmers markets and community supported agriculture. American Journal of Agriculture Economics, v. 90, p. 1296-1302, 2008.

BRUNORI, G. e MARESCOTTI, A. Looking for alternatives: the construction of the organic beef chain in Mugello, Tuscany. Int. J. Agricultural Resources, Governance and Ecology, v. 7, n. 1/2, 2008.

CADILHON, J. J. Grower direct marketing systems. Stewart Postharvest Review, v. 3, n. 3, p. 1-7, 2007. Disponível em: < http://www.stewartpostharvest.com/ vol3_2007/June_2007/Cadilhon.htm>.

ELDER, S. D., LISTER, J. e DAUVERGNE, P. Big retail and sustainable coffee: a new development studies research agenda. Progress in Development Studies, v. 14, p. 77-90, 2014.

FIELD, A. Descobrindo a estatística usando o SPSS. 2. ed. Porto Alegre: Bookman, 2009.

FONSECA, A. e GABRIEL, C. F. Análise da influência da tarifação em seis indicadores operacionais e de qualidade dos serviços de abastecimento de água no Brasil. Eng. Sanit. Ambient, v. 20, n. 2, p. 219-224, 2015.

GONZÁLEZ, A. A. e NIGH, R. Smallholder participation and certification of organic farm products in Mexico. Journal of Rural Studies, v. 21, n. 4, p. 449-460, out. 2005. Disponível em: < http://linkinghub.elsevier. com/retrieve/pii/S0743016705000690>. Acesso em: 4 nov. 2014.

HART, A. Mann-Whitney test is not just a test of medians: differences in spread can be important. BMJ: British Medical Journal, v. 323, n. 7309, p. 391, 2001.

HSU, J. S.-C. e CHEN, E. T. Managers' Perceived Benefits of Using Electronic Procurement in Taiwan. Communications of the IIMA, v. 4, n. 2, p. 3, 2015.

PHILLIPS, J. C. e PETERSON, H. C. Strategic marketing decisions for organic agricultural producers. International Food and Agribusiness Management Review, v. 10, n. 1, p. 100-114, 2007.

VORLEY, B. Corporate concentration from farm to consumer UK Food Group. London: UKFG, 2003. Disponível em: <http://www.ukfg.org.uk/docs/UKFG-FoodincNov03.pdf $>$.

. e FOX, T. Global Food Chains: Constraints and Opportunities for Smallholders Final Version. Helsinki: OECD, 2004.

WANG, H., MOUSTIER, P. e LOC, N. T. T. Economic impact of direct marketing and contracts: the case of safe vegetable chains in northern Vietnam. Food Policy, v. 47 , p. 13-23, ago. 2014. 